\title{
MATERIAIS LÍTICOS LASCADOS DA TRADIÇÃO ARATU-SAPUCAÍ NO NORTE DO ESTADO DE SÃO PAULO. O CASO DOS SÍTIOS TURVO V-A E TURVO V-B
}

\author{
Brendo Luiz Camargo Rosa, Neide Barrocá Faccio
}

Universidade Estadual Paulista - UNESP, Departamento de Planejamento, Urbanismo e Ambiente, Programa de pósgraduação em Geografia, Presidente Prudente, SP. E-mail: brendocamargo@gmail.com. Agência de fomento: Fundação de Amparo à Pesquisa do Estado de São Paulo - FAPESP

\section{RESUMO}

Este artigo apresenta os resultados de pesquisas arqueológicas realizadas durante os anos de 2014 e 2017 nas áreas dos Sítios Arqueológicos Turvo V-A e Turvo V-B. Estes sítios localizam-se na região Norte do Estado de São Paulo, sobre a Bacia Hidrográfica do Rio Turvo/Grande. Tratam-se de materiais associados à Tradição Arqueológica Aratu-Sapucaí. O trabalho em tela apresente a análise de 440 materiais líticos lascados dos dois sítios, onde foram identificadas diferenças na frequência de matérias-primas e categorias. Palavras-chave: Arqueologia; Norte do Estado de São Paulo; Aratu-Sapucaí; Lítico Lascado

\section{ARATU-SAPUCAÍ CHIPPED LITHIC TRADITION'S IN THE NORTH OF SÃO PAULO STATE. TURVO V-A AND TURVO V-B}

\begin{abstract}
This article presents the results of archaeological research carried out during the years 2014 and 2017 in the areas of Turvo V-A and Turvo V-B Archaeological Sites. These sites are located in the Northern region of the State of São Paulo, on a Grande/Turvo hydrographic basin. These are materials associated with the Aratu-Sapucaí Archaeological Tradition. The work on screen presents the analysis of 440 lithic materials of the two sites, where the frequency of chipped lithic and categories were identified.
\end{abstract}

Keywords: Archaeology, São Paulo Northern State, Aratu-Sapucaí, Chipped Lithic

\section{INTRODUÇÃO}

Apresenta-se, neste artigo, os resultados obtidos com o estudo da cadeia operatória de produção dos materiais líticos lascados dos Sítios Arqueológicos Turvo V-A e
Turvo V-B, localizados no Município de Pontes Gestal, SP, na área da Bacia Hidrográfica dos Rios Turvo/Grande (Figura 1).

Figura 1. Localização dos Sítios Arqueológicos Turvo V-A e Turvo V-B

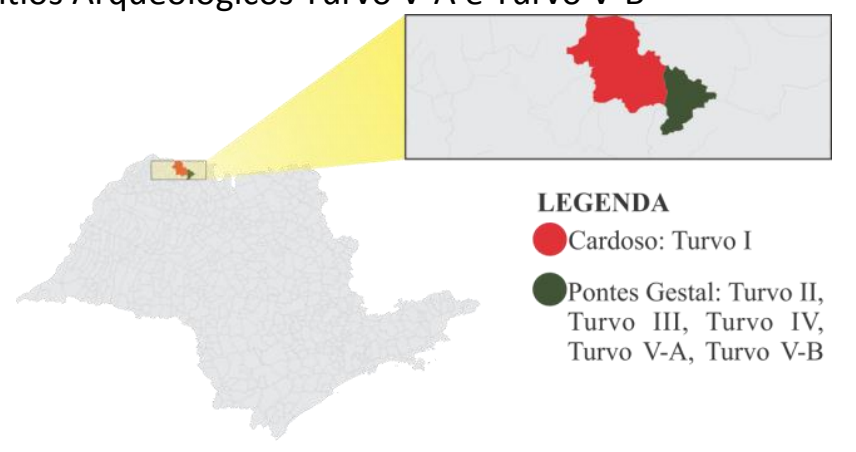

Fonte: O autor (2017). 
Trata-se de sítios da Tradição Arqueológica Aratu-Sapucaí. Os primeiros sítios arqueológicos ligados a essa tradição no Brasil foram encontrados por Valentín Calderón, na Bahia, e receberam seus nomes em referência à cidade onde os vestígios foram encontrados.
Além de São Paulo e Bahia foram localizados outros sítios arqueológicos ligados a essa tradição nos Estados do Espírito Santo, Goiás, Minas Gerais, Paraná e Tocantins, como apresenta a Figura 2, proposta por Schmitz e Rogge (2008).

Figura 2. Localização das Áreas de Ocorrências da Tradição Aratu no Brasil.

Fonte: Adaptado de Schmitz e Rogge (2008).

O passado da região norte do Estado de São Paulo, em seu contexto arqueológico, é ainda pouco conhecido.

Para Fernandes (2007),

a pré-história do norte de São Paulo ainda tem muito a revelar e por isso são inúmeras as abordagens que podem ser feitas. Somente com o tempo saberemos mais a respeito do modo de vida das populações pré-históricas [que ocuparam a região]. (FERNANDES, 2007, p. 201).

A realização do estudo dos materiais encontrados nos sítios arqueológicos fornece contribuições referentes às populações que os confeccionaram. Sabe-se que são poucos os estudos voltados ao passado dos grupos indígenas dessa região. Assim, pretende-se contribuir com dados da indústria lítica lascada dos sítios em tela.

Partindo-se dessa premissa, apresenta-se nesse artigo os resultados da pesquisa realizada entre os anos de 2014 e início de 2017. O trabalho, financiado pela Fundação de Amparo à Pesquisa do Estado de São Paulo (FAPESP), almejou contribuir para o conhecimento acerca das populações indígenas que viveram na região Norte do Estado de São Paulo no período précolonial. Nesse sentido, o estudo das indústrias de materiais líticos lascados encontrados na região. Foi realizada a partir de uma revisão bibliográfica dos principais autores que estudaram e analisaram indústrias líticas, a fim de elaborar um guia para o estudo dos materiais de acordo com o contexto em que se encontravam.

Por fim, apresentamos alguns artefatos líticos lascados dos dois sítios estudados, com a finalidade de demonstrar os resultados da análise do material e apontar diferenças entre as duas coleções, apesar da proximidade dos sítios.

\section{METODOLOGIA}

Os primeiros estudos na área da Arqueologia priorizaram a classificação tipológica, evidenciando que os instrumentos formais, tais como as pontas de flecha e os planos convexos eram os materiais mais importantes. 0 emprego da análise tecnológica ou tecnotipológica possibilitou entender o processo produtivo do artefato.

"Um utensílio não é somente uma forma, mas um esquema operatório [e] de um pensamento que resolveu um problema..." (BOEDA, 1997 apud Hoeltz, 2005, p.36). Até meados da década de 60 , os procedimentos teórico-metodológicos utilizados permaneceram com seu caráter tipológico. As interpretações tecnológicas começaram a ser valorizadas apenas a partir da metade do século XX - tardiamente com relação às outras ciências, influenciadas pelas pesquisas antropológicas. 
A fabricação de um material como um ato técnico é organizado em uma série de sequências e operações que se completam formando uma cadeia delas. Segundo Fogaça (2001), cadeia operatória é o processo que segue desde a coleta de matéria prima (blocos brutos, lascas corticais), debitagem de suportes (núcleos, lascas sem córtex...) até a produção de instrumentos (suportes retocados, lascas de façonnage).

O estudo das cadeias operatórias fornece uma visualização mais completa acerca das diferenças e similaridades dos primeiros objetos produzidos por grupos humanos. Com os resultados dessa análise, podem-se apontar diferenças significativas das tecnologias utilizadas entre os diversos grupos que habitaram determinada região.

Segundo Grace (1996), de maneira sintética, a cadeia operatória divide-se em: a) escolha da matéria-prima; b) redução primária, que é a limpeza inicial do material; c) redução secundária, que é a retirada de lascas e a manufatura de ferramentas com ou sem retoque; d) o uso das ferramentas; e) seu descarte posterior.

Partindo do pressuposto de que a escolha da matéria-prima seja o início da cadeia operatória, temos que a sua obtenção depende da maneira como ela será utilizada, fator indispensável para a sua seleção. Devem-se considerar, também, as dificuldades da coleta e do transporte do material até o local onde o instrumento será produzido, devido ao fato de que, muitas vezes, as rochas desejadas não eram encontradas nas proximidades. Nessa etapa também é de igual importância o estudo da paisagem do sítio, pois essa análise auxiliará na compreensão dos motivos de escolha daqueles locais para habitação/obtenção da matériaprima.

O estudo das cadeias operatórias é realizado por meio de estudo bibliográfico, análise dos materiais líticos lascados encontrados nos sítios e experimentação. Vale ressaltar ainda que as técnicas utilizadas pelos artesãos variam de acordo com seus objetivos e o contexto cultural.

\section{RESULTADOS}

A partir dos estudos realizados com os materiais líticos lascados e cerâmicos desses sítios, verificou-se que pertencem à Tradição Arqueológica Aratu-Sapucaí, vinculada aos grupos indígenas Kayapó.

Com isso, apresentam-se os líticos lascados estudados para as áreas dos Sítios Arqueológicos Turvo VA e Turvo VB. As categorias de análise foram definidas a partir da avaliação das coleções e da adaptação do guia para análise de materiais líticos lascados elaborados por pesquisadores do Laboratório de Arqueologia Guarani e Estudos da Paisagem da FCT/UNESP. O objetivo dessa forma de organização é apontar elementos e semelhanças que auxiliem na identificação do padrão de lascamento e, posteriormente, na cadeia operatória de produção.

No total, foram analisados 440 líticos lascados. O Sítio Turvo V-B apresentou a maior frequência de materiais, enquanto na área do Sítio Turvo V-A houve a ocorrência de 87 líticos lascados. A Figura 4 apresenta a organização dos materiais dos sítios arqueológicos em mesas, separados por matéria-prima.

Foto 1. Disposição dos líticos lascados da pesquisa para análise no LAG/FCT-Unesp.

Fonte: O autor (2017).

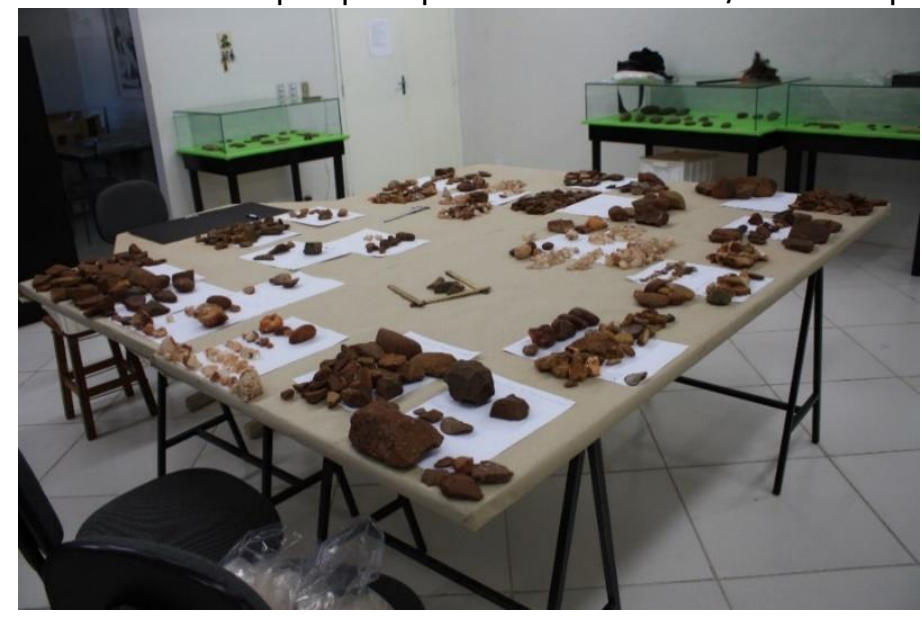


Fotos 2. Líticos lascados em basalto e arenito silicificado do Sítio Arqueológico Turvo V-A.

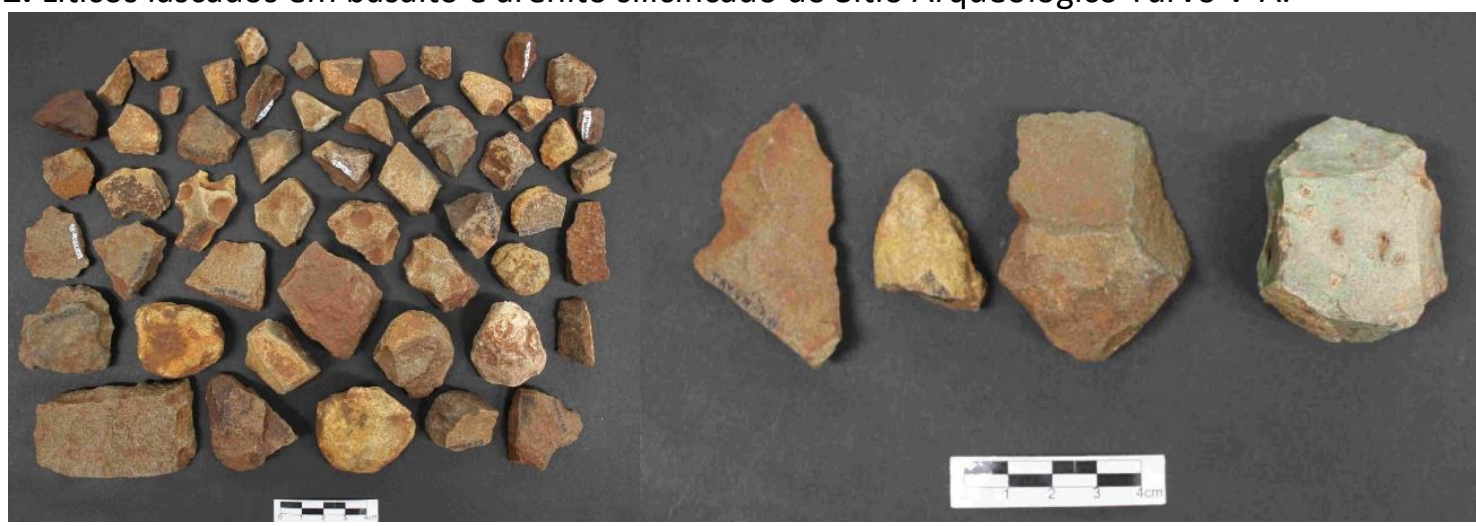

Fonte: O autor (2017).

Foto 3. Líticos lascados em quartzo e silexito do Sítio Turvo V-A.

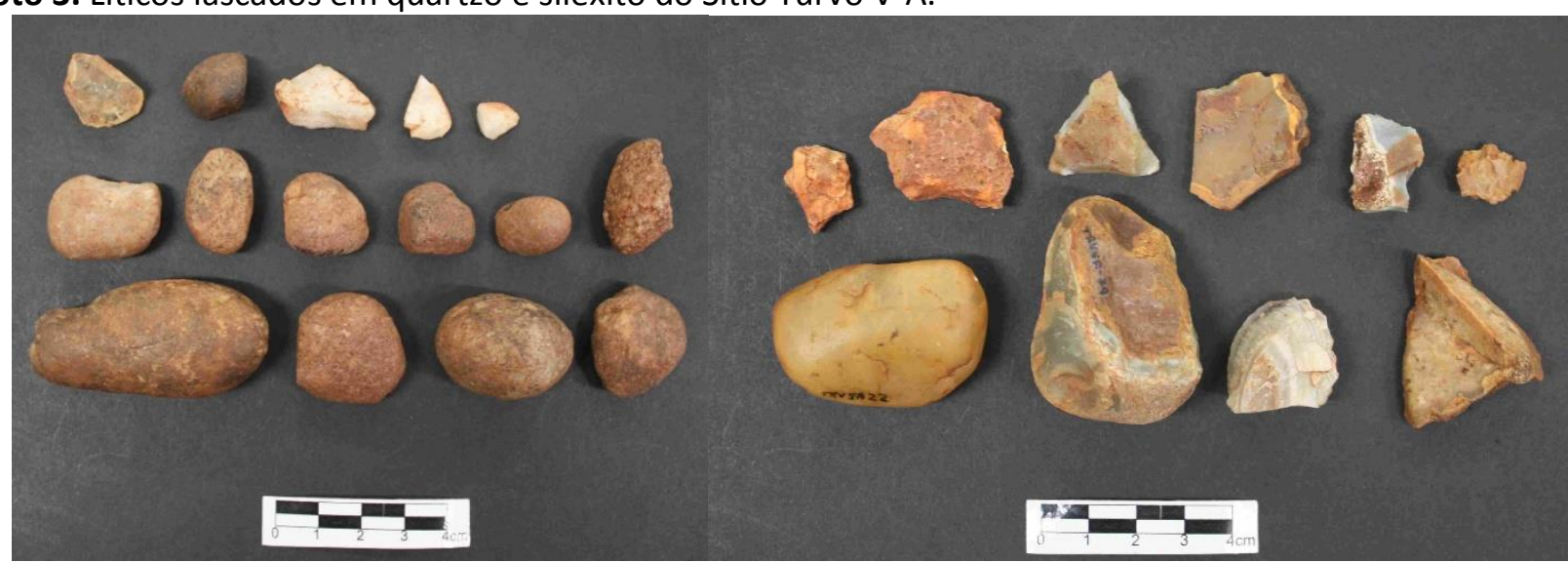

Fonte: O autor (2017).

O conjunto de líticos em silexito do Sítio Turvo V-A não apresentou materiais com marcas de utilização para lascamento. Nesse sentido, a análise tecnológica não pôde ser aprofundada.

O Sítio Arqueológico Turvo V-B possui uma coleção de 353 peças, em sua maioria de fragmentos de basalto (66 peças), seguidos de sílex (56 peças), quartzo (46 peças) e arenito silicificado (13 peças).

As fotos de 4 a 6 mostram as peças em arenito silicificado, quartzo e sílex do Sítio Turvo V-B.

Fotos 4 e 5. Líticos lascados em basalto e arenito silicificado do Sítio Turvo V-B.

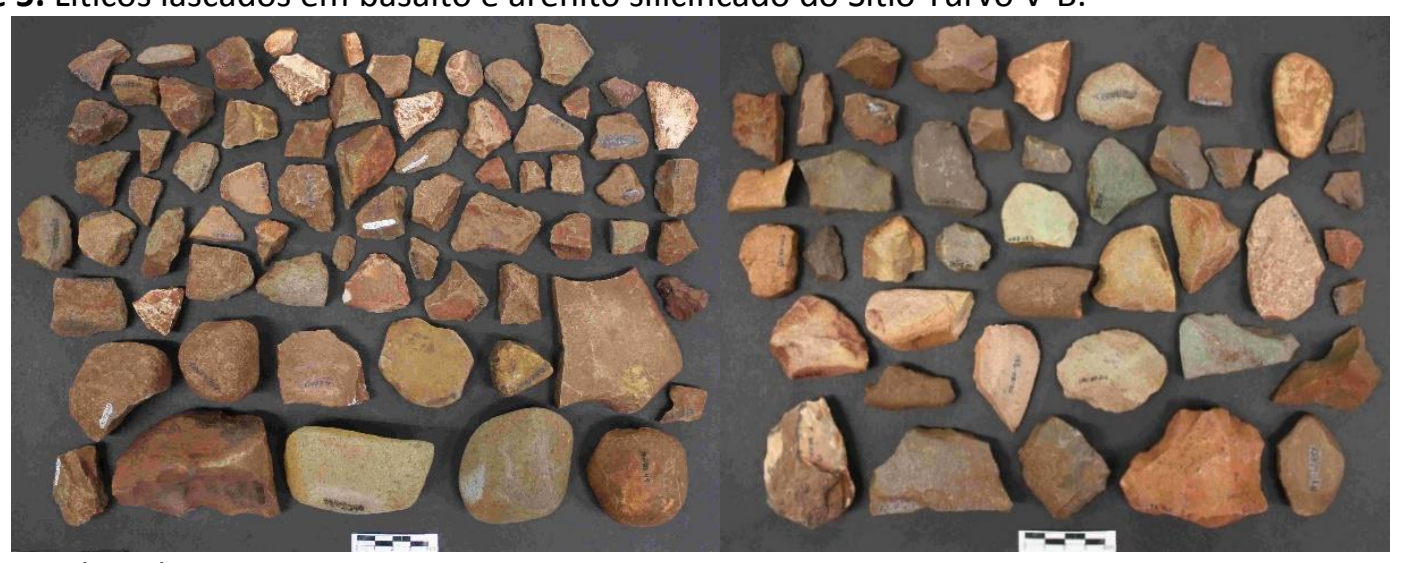

Fonte: O autor (2017). 
Figuras 11 e 12: Líticos lascados em do Sítio Turvo V-B.

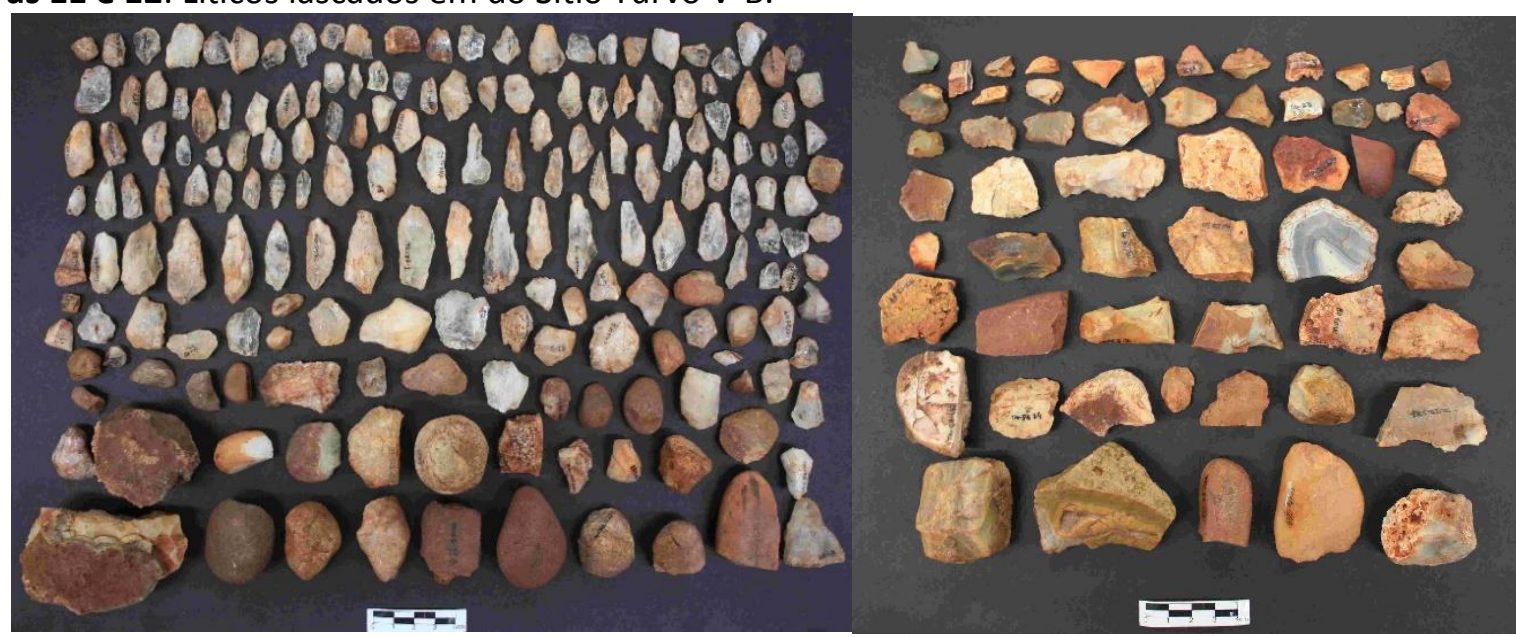

Fonte: O autor (2017).

Os materiais estudados foram resíduos de lascamento, lascas e seixos. É possível observar que os materiais trabalhados possuem suporte predominantemente sobre seixos. As lascas da coleção aparentam ter sido lascadas diretamente dos núcleos, possivelmente para imediata utilização, pois possuem gumes cortantes. Os resíduos de lascamento apresentam elementos de líticos lascados e podem ter sido gerados a partir da preparação do núcleo para a retirada de lascas. Os seixos não possuem elementos que os configuram como um percutor utilizado. As lascas dessa matéria-prima são bastante utilizadas por caçadores-coletores, em decorrência do resultado do lascamento que produz gumes cortantes de imediato, sem a necessidade de se trabalhar em retoques.

\section{DISCUSSÃO}

A hipótese trabalhada a partir das coleções leva a crer que as matérias primas disponíveis e abundantes na região foram bastante aproveitadas, pois é notável a vasta utilização de rochas de quartzo, silexito e arenito silicificado nas atividades de lascamento.

As lascas produzidas sobre cristais de quartzo apresentaram-se em dois modelos: lascamento do cristal sobre uma bigorna, utilizando-se um percutor duro, o que gerou lascas consideravelmente longas com bulbo, talão em um polo e esmagamento no outro polo, gerando os materiais em formato de prisma; lascas unipolares, produzidas por golpes, utilizando-se um percutor duro. Provavelmente são lascas preparatórias, visto não apresentarem elementos passíveis de utilização, como gumes cortantes e partes preensivas. Nesse sentido, conclui-se que a hipótese de cadeia operatória de produção dos cristais de quartzo dessas coleções constituiu-se de retiradas preparatórias em núcleos em formato de cristais e posterior lascamento sobre bigorna. Não houve a ocorrência de retoques ou reavivagem do gume.

Observou-se a ocorrência de padrões de lascamento sobre as matérias-primas arenito silicificado e silexito, que seguiram ordens semelhantes: retiradas de núcleos utilizando-se percutores duros sem o apoio em uma bigorna, gerando lascas com gumes cortantes e sem a necessidade de retiradas secundárias. Não foram identificados retoques ou reavivagem de gumes.

Foram evidenciadas poucas peças com morfologia completa; no entanto, considerando a grande frequência de lascas, resíduos e fragmentos no mesmo contexto arqueológico, entende-se que os locais foram bastante utilizados para a produção de materiais líticos lascados. O Sítio Turvo V-B apresentou lascas que foram utilizadas além de compostos das mesmas matérias-primas abundantes no local com possíveis utilizações, vistas através de gumes levemente denticulados. Já os núcleos analisados apresentaram-se bem esgotados com alguns negativos em sua morfologia.

\section{CONCLUSÃO}

O estudo da coleção lítica lascada dos Sítios Arqueológicos Turvo V-A e Turvo V-B demonstrou que suas peças foram confeccionadas, principalmente, a partir da matéria-prima quartzo, seguida do basalto. 0 arenito silicificado e o silexito aparecem em pouca quantidade, se comparado ao quartzo e ao basalto estão presentes em menor quantidade nos sítios investigados. Os cristais de quartzo aparecem em maior quantidade e possuem 
morfologia prismática; suas lascas apresentaram gume cortante e podem ter sido lascados tanto por percussão direta quanto por percussão direta sobre bigorna.

$\mathrm{Na}$ área do Sítio Turvo V-A, foram encontrados 87 líticos lascados, quatro líticos polidos e 820 fragmentos de cerâmica. Já na área do Sítio Turvo V-B foram resgatados 353 líticos lascados, três líticos polidos e 32.095 fragmentos de cerâmica. Mesmo sendo sítios próximos foi possível notar diferença no uso das matériasprimas dos dois sítios, assim como a frequência dos materiais.

\section{REFERÊNCIAS}

FERNANDES, T. C. Vamos Criar um sentimento?! um olhar sobre a arqueologia pública no Brasil. 2007. Dissertação (Mestrado em Arqueologia) Museu de Arqueologia e Etnologia,Universidade de São Paulo, São Paulo, 2007.

FOGAÇA, E. Mãos para o pensamento: a variabilidade tecnológica de indústrias líticas de caçadores-coletores holocênicos a partir de um estudo de caso: as camadas VIII e VII da Lapa do Boquete (Minas Gerais, Brasil - 12.000/10.500 B.P) 2001. 452 f. Tese (Doutorado) - Pontifícia Universidade Católica do Rio Grande do Sul, Porto Alegre, 2001.

GRACE, R. "Châine opératoire" approach to lithic analysis.

<http://hf.uio.no/iakk/roger/lithic/opchainpaper. html\#anchor94966>. Acesso em: 10 nov. 2016

HOELTZ, S. E. Tecnologia lítica: uma proposta de leitura para a compreensão das indústrias do Rio Grande do Sul, Brasil, em tempos remotos. 2005. Tese (Doutorado em Arqueologia) - Programa de Pós-Graduação em História, Pontífica Universidade do Rio Grande do Sul, Porto Alegre, 2005.

SCHMITZ, P.I.; ROGGE, J.H. Um sítio da tradição cerâmica Aratu em Apucarana, PR. Revista do Museu de Arqueologia e Etnologia, São Paulo, n. 18, p. 47-68, 2008. Disponível em: https://doi.org/10.11606/issn.2448-

1750.revmae.2008.89828. Acesso em: 15 nov. 2016
Recebido para publicação em 16/08/2017

Revisado em 18/09/2017

Aceito em 22/09/2017 